\title{
MERCADO ESCOLAR, DE TRABALHO E USOS DA TITULAÇÃO UNIVERSITÁRIA
}

\section{MARKET SCHOOL, OF LABOR AND USES OF THE UNIVERSITY DEGREE}

\author{
Odaci Luiz Coradini*
}

\section{Introdução}

0 presente texto expõe os resultados da pesquisa sobre as relações entre condições de ingresso no ensino universitário e expectativas de exercício profissional. Com base nos microdados do Exame Nacional de Desempenho de Estudantes (ENADE) de 2005 e do Exame Nacional de Cursos (Provão) de 2003, num primeiro momento são apresentados os resultados da análise dos principais indicadores relativos às condições de ingresso nos cursos universitários abrangidos. E, num segundo momento, são expostas as relações dessas condições com as pretensões quanto às possibilidades de exercício profissional. A hipótese geral é a de que, em configurações como as que atualmente regem o ingresso e a hierarquização do ensino superior no Brasil, o capital escolar tem condições muito restritas de expressar algum grau significativo de autonomia frente a outras espécies de capital e esferas de atividade. Consequentemente, se, por um lado, ocorre um forte grau de associação entre os indicadores de origens e de posição social com os recursos escolares, por outro lado, os recursos de origens sociais variam quase sempre na mesma direção e grau dos recursos escolares. Isso se manifesta na divisão entre os cursos quanto à sua importância nos mercados profissionais e econômicos, no desempenho escolar e nas preferências de exercício profissional. Como se trata de condições extremamente diferenciadas de ingresso no mercado escolar, além dos indicadores mais convencionais de origens e posição social, destaca-se também a relevância daqueles ligados às relações com o grupo familiar de origem, ou por aliança, à situação no ciclo de vida, ao

\footnotetext{
* É doutor em antropologia social, professor e pesquisador do Programa de Pós-graduação em Ciência Política (UFRGS, Porto Alegre/RS). Bolsista produtividade em pesquisa do CNPq. coradini@portoweb.com.br
} 
ingresso mais precoce ou tardio nos mercados de trabalho e escolar, juntamente com os diferentes significados da escolarização e do trabalho profissional que comportam.

0 problema das relações diferenciadas com o espaço escolar e seu grau de autonomia frente a outros recursos sociais e esferas de atividade pode ser formulado de modo apriorístico e abstrato numa espécie de busca de algum "campo" deduzido por analogia, suprimindo a importância heurística dessa problemática. Mesmo que tenha sido formulado tendo como referencial outras configurações históricas e sociais, esse problema pode ser sociologicamente muito fértil se a autonomia relativa não for tomada como premissa ou algum conceito em abstrato, mas como hipótese de trabalho. Em sua formulação original, nas relações entre as estruturas sociais e as hierarquias escolares, as instituições de ensino superior se dividem, "de um lado, conforme o grau de autonomia”, conseguindo impor "critérios de seleção técnicos, mas também éticos, especificamente escolares”, diferentes daqueles do mercado; e, por outro lado, "conforme o volume do capital escolar que os alunos detêm e a estrutura de capital que estes herdaram de sua família” (BOURDIEU, 1989, p. 213). Desse modo, a hierarquia das instituições corresponde à hierarquia das origens e das qualidades sociais dos alunos. No entanto, atua também um segundo princípio, com base especificamente no capital escolar, que depende diretamente das classificações escolares, do grau de autonomia e da possibilidade de reconversão do capital cultural de origem (BOURDIEU; SAINT MARTIN, 1987). Outra hipótese perseguida no trabalho é aquela conforme a qual, tanto no que tange ao mercado escolar como no que diz respeito ao mercado profissional, tratam-se de "mercados múltiplos” (ZELIZER, 1992) e, em graus e condições variadas, de "mercados controlados” (BOURDIEU; CHRISTIN, 1990).

\section{0 material empírico e as principais téc- nicas utilizadas}

0 presente artigo é produto do aproveitamento parcial de resultados de uma investigação mais ampla centrada no estudo dos professores e das transformações no ensino superior $^{1}$. As principais fontes do trabalho mais geral consistem em arquivos de microdados do IBGE (Instituto Brasileiro de Geografia e Estatística) e do INEP (Instituto Nacional de Estudos e Pesquisas Educacionais Anísio Teixeira). No caso do INEP, entre outros bancos de dados, foram estudados aqueles relativos ao Exame Nacional de Cursos (Provão) e do Exame Nacional de Desempenho de Estudantes (ENADE). 0 Provão é um exame aplicado aos formandos em cursos superiores no período de 1996 a 2003. Os cursos privilegiados variaram para cada edição. Na edição aqui utilizada como fonte, foram incluídos 6.500 cursos de 26 áreas ou "carreiras", que são os que seguem: administração, direito, engenharia civil, engenharia química, medicina veterinária, odontologia, matemática, jornalismo, letras, engenharia elétrica, engenharia mecânica, medicina, economia, física, química, biologia, agronomia, psicologia, farmácia, pedagogia, arquitetura e urbanismo, ciências contábeis, enfermagem, história, fonoaudiologia e geografia. Conjuntamente com as provas, nesses exames foi solicitada aos alunos a resposta a um questionário socioeconômico do qual foi extraída a maior parte das informações utilizadas (além dos resulta-

1. Realizada com o apoio do INEP/CAPES/Observatório da Educação (Projeto 003-Edital 001/2006). 
dos das provas). Na edição de 2003 houve a participação de um total de 407.419 alunos que preencheram esse questionário $(86,37 \%$ dos inscritos nas provas). Para a reflexão ora realizada, foram incluídos na análise somente os que responderam.

O Enade, por sua vez, teve início em 2004 e é realizado com base numa amostragem de alunos habilitados a fazer a avaliação. Ainda que haja diferenças com relação ao Provão quanto às provas, há um questionário socioeconômico muito semelhante. Tendo isso em vista, a inclusão dos resultados de uma edição do Enade teve por objetivo principal aumentar a quantidade e a diversidade dos cursos no universo estudado. A edição de 2005 era a última disponível em microdados quando da realização da análise. Nesse ano, um total de 213.002 alunos, sobre 258.932 inscritos, responderam ao questionário. As áreas ou "carreiras" incluídas nessa edição foram as que seguem: matemática, letras, física, química, biologia, pedagogia, arquitetura e urbanismo, história, geografia, filosofia, computação e engenharias (divididas em oitos grupos) ${ }^{2}$.

Quanto às técnicas de análise, as mais utilizadas consistiram em testes de análise de correspondência múltipla e tabelas cruzadas. Algumas ilustrações dos resultados desses testes estatísticos estão em quadros ao longo do texto.

\section{Relações entre recursos sociais, hierar- quização escolar e mercados de trabalho de destino para os alunos do Enade 2005 e do Provão 2003}

A análise das condições de ingresso no mercado escolar, apesar da relativa precariedade do material disponível ${ }^{3}$ exige considerar o peso de determinados indicadores sociodemográficos e suas implicações. Os mesmos se referem, notadamente, a atributos como: idade, número de irmãos, estado civil, número de filhos, com quem reside durante a realização do curso universitário, a quantidade de tempo dedicado a atividades remuneradas, além dos indicadores mais diretos relativos às origens e posição social. Esse peso decisivo das variáveis sociodemográficas aponta para a importância das modalidades de vinculação com o grupo familiar, de origem ou por aliança, nas condições de ingresso no mercado escolar; e ainda permite evidenciar que, se um dos principais recursos investidos no campo escolar consiste no tempo dedicado à escolarização, a disponibilidade desse tempo está condicionada pelo estágio no ciclo de vida, pela posição no respectivo grupo familiar e, assim, pelas chances de ingresso no mercado de trabalho mais precoce ou mais tardiamente, além dos recursos econômicos e culturais de origem.

2. No Enade 2005 os cursos de engenharia foram classificados nos seguintes grupos: engenharia grupo I: civil, sanitária, cartográfica, geológica, hídrica e agrimensura; grupo II: computação, controle e automação, eletrônica, eletrotécnica, e telecomunicações: grupo III: engenharia; grupo IV: industrial química, bioquímica, biotecnologia, alimentos e têxtil; grupo V: materiais, materiais metálicos, materiais cerâmicos, materiais poliméricos, materiais plásticos, metalurgia, fundição, e engenharia física; grupo VI: produção, produção civil, produção de materiais, produção elétrica, produção mecânica, produção química, e produção têxtil; grupo VII: engenharia ambiental, de minas, de petróleo, e industrial madeireira; grupo VIII: agrícola, de pesca e florestal.

3. Nos respectivos questionários socioeconômicos do Provão e do Enade foi excluída a questão relativa à ocupação ou profissão dos pais dos alunos, que foi mantida para os alunos do ENEM (Exame Nacional do Ensino Médio). 
Isso pode estar relacionado com a configuração de algum grau de autonomia do espaço escolar e de alguma independência entre as condições sociais de existência e a situação no mercado escolar. A própria distribuição dos alunos (conforme as distintas condições e as formas institucionais) está associada àqueles indicadores sociodemográficos. Como é demonstrado adiante, as pretensões quanto ao ingresso e às modalidades de exercício profissional estão igualmente condicionadas por esses recursos decorrentes das relações com o respectivo grupo familiar, o estágio no ciclo de vida e as condições institucionais de ingresso no mercado escolar.

A subordinação completa dos cursos mais diretamente vinculados às disciplinas "básicas" em relação àquelas de maior “aplicação prática” expressa uma das principais discrepâncias relativamente às situações nas quais é percebida uma maior autonomia do espaço escolar, como no caso francês, no qual há a formação de um polo que é tanto escolarmente mais forte quanto econômica e socialmente menos dominante (BOURDIEU, 1984). Ao contrário, nas condições estudadas, que são de inexistência desse tipo de autonomia, a hierarquização escolar está associada ao significado econômico de cada curso e, assim, os cursos centrados em disciplinas sem caráter de aplicação prática tendem a se posicionar no extremo do polo correspondente às piores condições, tanto em termos socioeconômicos como escolares.

Isso pode ser demonstrado com os dados do Enade e do Provão, embora com algumas dificuldades técnicas, como a já mencionada exclusão das informações relativas à ocupação dos pais. Além disso, como em cada ano esse tipo de exame abrange apenas alguns cursos, não se tem oportunidade de análise do conjunto num mesmo ano. Apesar de seu caráter parcial, a composição dos microda- dos disponiveis em 2005 e 2003, respectivamente, é representativa, visto que inclui aqueles cursos socialmente mais importantes, como os das engenharias, e outros menos "tradicionais", afora aqueles relacionados a disciplinas "básicas”, mais associadas à formação de professores, ou até mesmo cursos com caráter de "refúgio".

Numa primeira exploração do conjunto, foi aplicado um teste de análise de correspondência múltipla no qual foram incluídas as seguintes variáveis ativas do Enade 2005: a categoria administrativa da instituição de ensino, o tipo de organização acadêmica da instituição, a idade, a frequência no turno matutino, vespertino ou noturno, estado civil, número de filhos, com quem morou a maior parte do período do curso, renda mensal da família, modalidades de trabalho remunerado de que participa, grau de escolarização do pai e da mãe, tipo de escola do ensino médio e, por fim, tipo de curso no ensino médio. Como variáveis ilustrativas foi incluído o conceito final nas provas, o curso e a média nas provas, dentre outras. Nesse teste, os eixos obtiveram as seguintes porcentagens (inércia): 10,41\% (0,3110 de valor próprio) no primeiro, 6,70\% (0,2120 de valor próprio) no segundo, e 3,98\% $(0,1188$ de valor próprio) no terceiro eixo. Para a formação do primeiro eixo, a contribuição de cada variável é a que segue: a idade $(11,8 \%)$, com quem mora $(12,0 \%)$, o estado civil $(11,9 \%)$, o número de filhos $(10,8 \%)$, as modalidades de trabalho remunerado exercido (8,4\%), o grau de escolarização do pai (8,9\%) e da mãe $(9,2 \%)$, o tipo de curso do ensino médio $(7,4 \%)$, o tipo de escola do ensino médio $(4,3 \%)$, a frequência no turno noturno $(3,5 \%)$, no turno matutino (3,5\%), no turno vespertino $(2,2 \%)$, a renda da família $(2,4 \%)$, a categoria administrativa da instituição $(1,9 \%)$ e, por fim, o tipo de organização acadêmica da insti- 
tuição (1,7\%). Para a formação do segundo eixo, a contribuição das variáveis é a seguinte: a frequência no turno noturno (18,3\%), no turno matutino $(17,2 \%)$, a categoria administrativa da instituição $(14,6 \%)$, a frequência no turno vespertino (14,3\%), o tipo de organização acadêmica da instituição (8,5\%), com quem mora
(5,1\%), o número de filhos (4,4\%), o estado civil $(3,8 \%)$, a idade $(3,2 \%)$, a modalidade de trabalho remunerado $(3,4 \%)$, o grau de escolarização do pai $(2,4 \%)$ e da mãe $(2,2 \%)$, o tipo de curso do ensino médio (0,9\%), o tipo de escola do ensino médio $(1,0 \%)$, e, por fim, a renda familiar (0,5\%).

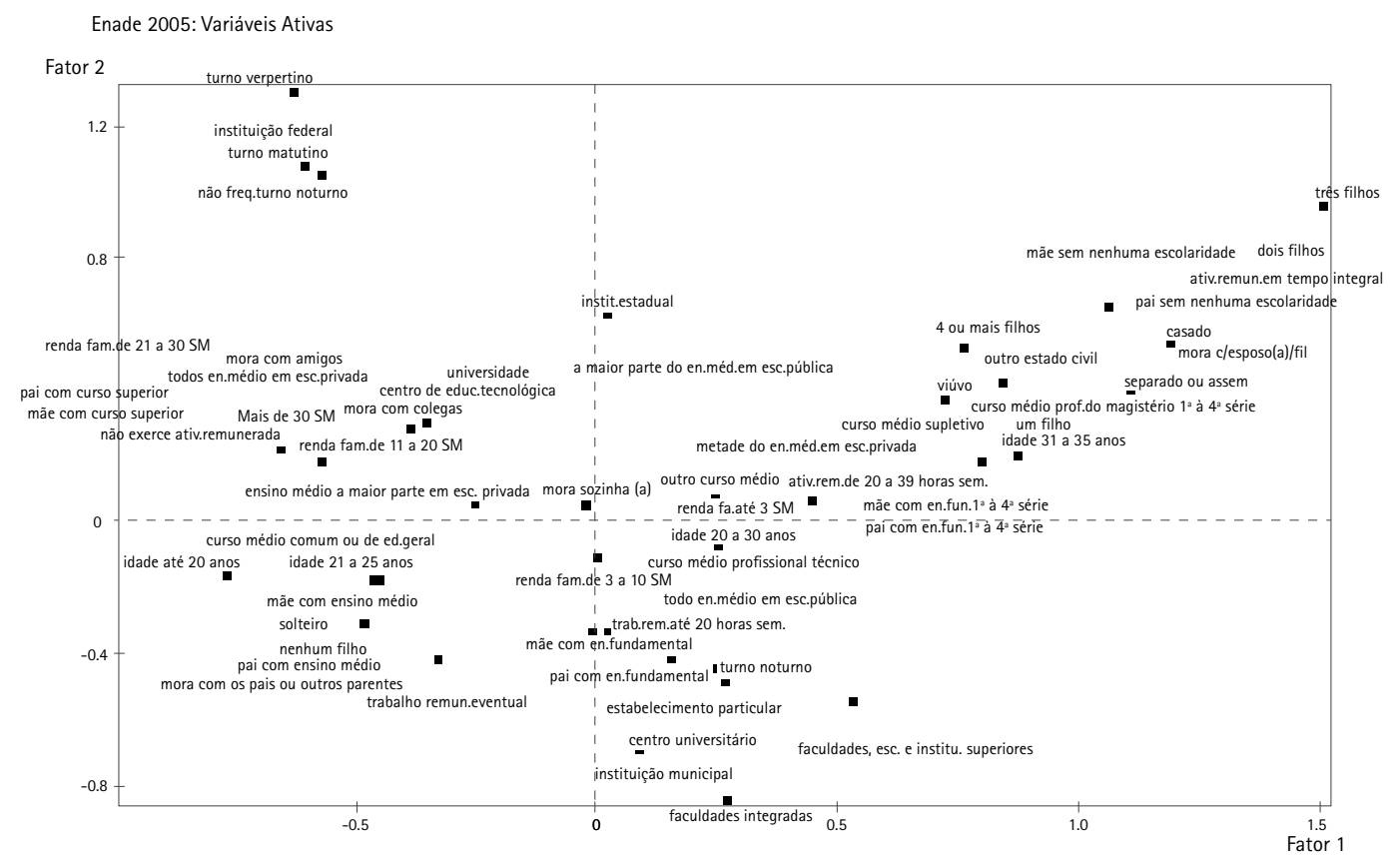

Numa primeira aproximação, na conf1guração dos resultados relativos aos alunos do Enade 2005, um primeiro polo é constituído por aqueles em melhores condições quanto às origens e posição social, bem como em relação à situação no grupo familiar, no ciclo de vida e frente ao ingresso precoce ou não no mercado de trabalho.

Esse primeiro polo - do primeiro eixo - está associado aqueles em que pai e mãe possuem curso superior ou médio, e renda familiar mais alta. Tais condições sociais mais favoráveis incluem a maior proporção dos que são mais jovens, solteiros, morando com os pais e que nunca exerceram qual- quer atividade remunerada. As vantagens referentes ao trajeto escolar incluem a realização do ensino médio comum de educação geral no curso regular realizado em escola particular - e quanto ao curso de graduação, há a maior proporção de matriculados em instituições federais, organizadas como universidades, frequentando o turno matutino ou vespertino. No que diz respeito aos resultados do Enade 2005, esse polo, que é correspondente às melhores condições sociais e escolares, aparece associado aos conceitos mais altos (5 e 4) e se refere aos cursos de arquitetura e urbanismo, engenharias, computação e, em menor grau, biologia. 
0 segundo polo - ainda do primeiro eixo - abrange aqueles em piores condições sociais e escolares, em termos de origens e posição social. Eles têm pai e mãe sem qualquer escolarização ou com apenas o correspondente ao ensino fundamental. São mais velhos, com maior proporção de casados, com mais filhos e mais tempo dedicado ao trabalho remunerado. Em termos escolares, estão mais diretamente associados aos que concluíram o ensino médio profissional de magistério de $1^{\text {a }}$ a $4^{\text {a }}$ série, tendo cursado todo o ensino médio em escola pública. No curso de graduação estão vinculados a faculdades, escolas e institutos superiores (em oposição às universidades), matriculados em instituição particular ou municipal e no turno da noite. Quanto aos resultados no Enade 2005, entre esses em desvantagem em termos sociais e escolares, correspondem mais diretamente os conceitos mais baixos (3 e 2) e as opções de cursos estão mais relacionadas aos de pedagogia e letras, ou seja, dirigidos à formação de professores do ensino de fundamental e médio.

Ainda no que concerne ao Enade 2005 - um segundo eixo é constituído pelos investimentos em recursos escolares, o que não exclui as origens e a posição social. 0 primeiro polo desse eixo é formado por aqueles em condições sociais e escolares mais precárias, embora não exclusivamente; seus pais têm o equivalente ao ensino fundamental, e proporcionalmente a certos atributos, a maioria deles: solteiros, sem filhos, mais jovens, com trabalho remunerado eventual, morando com os pais e/ou outros parentes e com renda familiar relativamente baixa. Quanto aos recursos escolares e institucionais, a esse polo correspondem aqueles que realizaram todo o ensino médio em escola pública e, no curso de graduação, frequentaram instituições de ensino particular ou municipal, organizadas como faculdade integrada, centro universitário ou faculdade, escola ou instituto superior, particularmente no noturno. Nesse polo, observam-se ainda os conceitos mais baixos (3 e 2) em cursos como alguns de computação, letras, engenharia e matemática.

Por fim, um quarto grupo relativo ao Enade 2005, corresponde ao polo contrário nesse segundo eixo, que apresenta características sociais bem heterogêneas e significativos recursos escolares. Quanto ao grau de escolarização dos pais, estão mais diretamente associados com aqueles cujo pai e mãe não têm qualquer escolarização, mas também com aqueles que possuem curso superior. Além disso, são proporcionalmente mais velhos, casados, morando com o (a) esposo (a), com mais filhos, trabalhando em tempo integral, mas inclui igualmente alguns sem atividade remunerada. Quanto ao trajeto escolar, têm maior participação os que cursaram todo o ensino médio em escola privada, e na graduação estão em maior proporção os que frequentam o turno matutino ou vespertino, em instituição estadual ou federal, organizada como universidade. Além dessas melhores condições institucionais, também se destacam pelo melhor desempenho no Enade 2005, aparecem associados aos conceitos mais altos (5 e 4). No que concerne aos cursos, se destacam os de engenharia dos grupos I e V (ver nota de rodapé 2), de arquitetura e urbanismo e, em menor grau, os de física.

Também numa primeira aproximação, para o Provão 2003 foi aplicado um teste de análise de correspondência múltipla, tendo como variáveis ativas basicamente as mesmas tomadas para o ENADE 2005. Aqui os eixos obtiveram as seguintes porcentagens (inércia): o primeiro atinge 10,3\% (com 0,3014 de valor próprio) 
e o segundo 6,10 (0,1832 de valor próprio). As variáveis que mais contribuem para o primeiro eixo, por ordem de importância, são as que seguem: a idade (12,2\%), com quem morou durante a maior parte do curso $(10,8 \%)$, estado civil (10,6\%), grau de escolarização da mãe $(10,5 \%)$ e do pai $(10,2 \%)$, quantidade de filhos $(9,9 \%)$ e, com menor peso: o tipo de curso do ensino médio $(7,4 \%)$, o tipo de escola de ensino médio (5,5\%), o número de irmãos (5,7\%), a carga horária do eventual trabalho durante 0 curso (4,9\%), a renda mensal da família $(3,3 \%)$, a frequência no turno matutino $(3,1 \%)$, frequência no turno noturno $(3,0 \%)$, frequência no turno vespertino (1,1\%), o tipo de organização acadêmica $(1,0 \%)$ e, por fim, a categoria ad- ministrativa da instituição (0,9\%). Para o segundo eixo: a frequência no turno matutino $(17,4 \%)$, frequência no turno noturno $(18,6 \%)$, frequência no turno vespertino $(14,7 \%)$ e a categoria administrativa da instituição $(11,4 \%)$. Com contribuição menor ou quase nula nesse segundo eixo: a organização acadêmica da instituição $(7,1 \%)$, com quem morou durante o curso (5,3\%), a carga horária do trabalho durante o curso (5,5\%), a quantidade de filhos $(3,0 \%)$, a quantidade de irmãos $(2,4 \%)$, o grau de escolarização do pai $(3,1 \%)$, o tipo de curso de ensino médio (2,9\%), o grau de escolarização da mãe (2,7\%), idade (2,4\%), estado civil $(1,6 \%)$, renda da família $(1,9 \%)$ e, por fim, o tipo de escola do ensino médio $(0,2 \%)$.

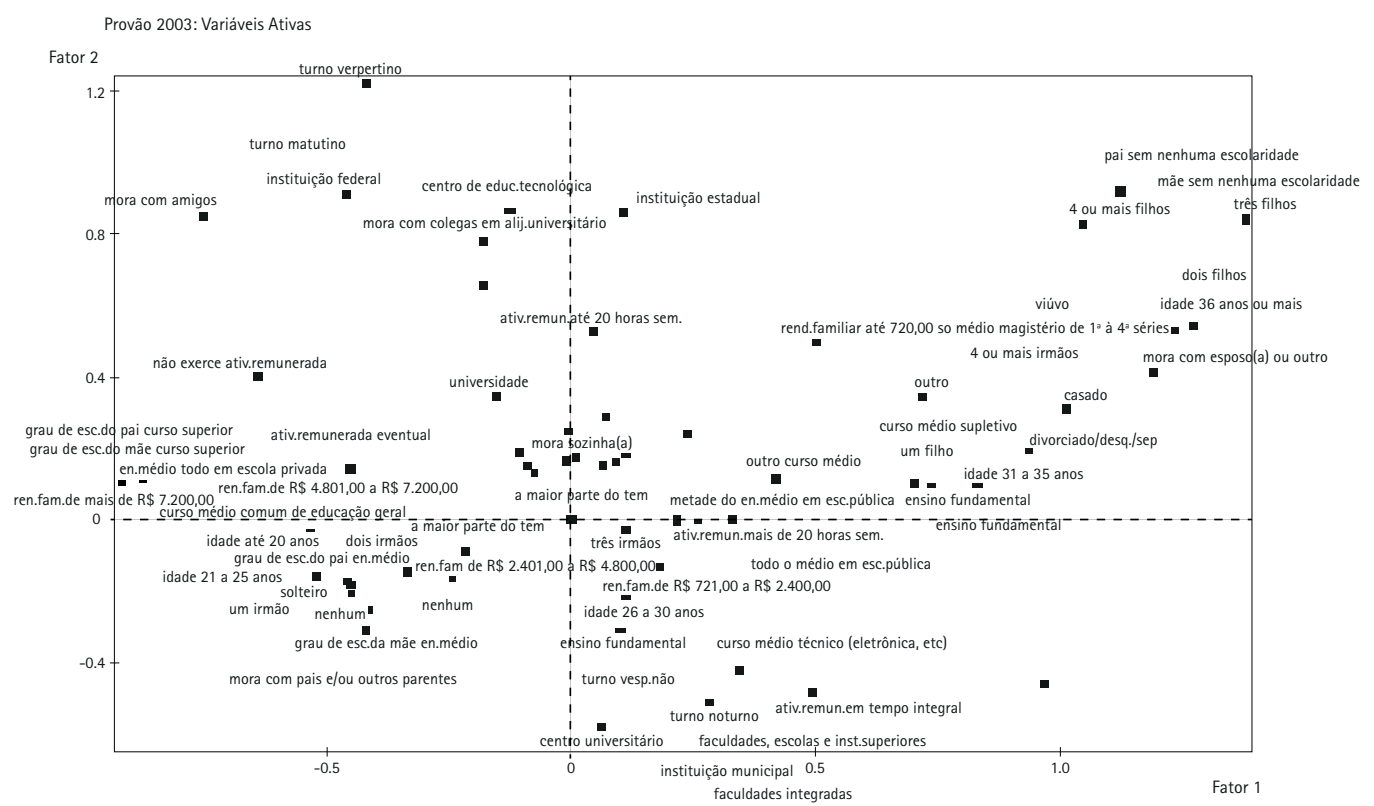

Para os alunos do Provão 2003 os resultados são muito semelhantes, mas sua inclusão teve a vantagem de acrescentar cursos excluídos do Enade 2005. Neste caso, também um primeiro polo é formado por aqueles em melhores condições tanto sociais como escolares, com pai e mãe com grau de escolarização mais alto e com renda familiar nas faixas mais elevadas. Além disso, nele há uma maior proporção de solteiros, com menos irmãos, são mais jovens e há também uma maior proporção dos que se consideram brancos. Quanto aos resultados no Provão 2003, esse polo está mais diretamente asso- 
ciado aos que obtiveram o maior conceito (5) e aos cursos de odontologia e medicina e, de modo menos intenso, também aos de farmácia, direito, medicina veterinária, arquitetura e urbanismo, engenharia civil, agronomia, psicologia e engenharia elétrica.

No polo contrário desse primeiro eixo, correspondendo às piores condições sociais e escolares, nas origens sociais se encontram pais e mães com apenas o ensino fundamental ou sem qualquer grau de escolarização e com renda familiar nas faixas mais baixas. Adiciona-se a isso que os agentes são mais velhos, com maior proporção de negros, dos que trabalham em tempo integral, que têm a maior quantidade de irmãos e com maior proporção de casados. Quanto ao trajeto escolar, acentuam-se aqueles que concluíram o supletivo ou o magistério de $1^{\text {a }}$ a $4^{a}$ série do ensino regular ou o técnico em eletrônica no ensino médio, com todo o ensino médio em escola pública, e na graduação frequentam o turno da noite, em instituição com organização acadêmica de faculdade, escola ou instituto superior. No Provão 2003, estão diretamente associados aos conceitos mais baixos (2 e 1) e, no tocante aos cursos, destacam-se os de pedagogia, letras, matemática, história, geografia, e ciências contábeis. Ou seja, com exceção desse último, todos os demais dirigidos à formação de professores de ensino fundamental e médio.

Como para o Enade 2005, também aqui um segundo eixo de oposição é constituído pelas variáveis de cunho escolar, sem excluir o peso das origens e da posição social. Nesse caso, num primeiro polo, referente às piores condições sociais e escolares, se sobressai aqueles cujas origens sociais apontam para pais e mães com somente o ensino fundamental ou médio e com renda familiar nas faixas mais baixas. No tocante às variáveis de cunho sociodemográfico, nesse polo estão as faixas etárias de médias a altas, com maior proporção de brancos, solteiros, com um irmão, sem filhos, ou seja, com algumas vantagens quanto a esses aspectos, mas que trabalham em tempo integral. Sobre o percurso escolar, acentuam-se os que cursaram o técnico em eletrônica no ensino médio e, no curso de graduação, estudam em instituições periféricas, isto é, faculdades, escolas e institutos superiores ou centros universitários ou, ainda, em faculdades integradas, no turno noturno, em instituições particulares e, em menor grau, municipais. No Provão 2003, a esse polo correspondem mais diretamente os conceitos médios e baixos (particularmente 3 e 2) e se destacam os cursos de administração, ciências contábeis, direito, economia e jornalismo, quer dizer, todos incluídos ou próximos das chamadas "ciências sociais aplicadas".

Por fim, uma categoria que pode ser identificada no Provão 2003 por se caracterizar pelas condições sociais muito baixas, mas que, em termos escolares, se situa acima da média. Aliás, constitui-se em um dos poucos casos de uma relativa dissociação entre as condições sociais e as escolares, relativamente a alguns aspectos. No que diz respeito às origens sociais, a esse último polo do segundo eixo correspondem aqueles cujos pais têm baixo grau de escolarização, e com a renda familiar muito baixa. No que se refere aos demais indicadores de cunho sociodemográfico, constam, sobretudo pardos ou mulatos, negros ou amarelos, casados, com mais irmãos, tendo atividade remunerada durante o curso e com mais filhos. Quanto ao trajeto escolar, têm desvantagens no ensino médio, tendo concluído em uma maior proporção o magistério de $1^{\text {a }}$ a $4^{\text {a }}$ série no ensino regular. Porém, na graduação, contam com a vantagem de frequentar instituições mais 
centrais, como universidade federal ou estadual. No Provão 2003, a esse polo corresponde diretamente o conceito mais alto (5) e os alunos são de cursos de pedagogia, medicina, odontologia, agronomia, enfermagem, farmácia e medicina veterinária.

Portanto, se por um lado ocorre um forte grau de associação entre os indicadores de origens e posição social e os de recursos escolares, por outro lado, o capital escolar não apresenta qualquer grau significativo de autonomia. Isso se manifesta igualmente na distribuição entre disciplinas e respectivos mercados dos cursos. Porém, nessas condições, a clássica oposição entre as disciplinas "básicas” e as de "aplicação prática" muda de sentido. Isso porque, mais que o conteúdo ou a "aplicação" do conhecimento, o determinante primordial passa a ser as condições de ingresso em mercados profissionais específicos, socialmente diferenciados e hierarquizados. Como também já foi mencionado, em geral, o extremo inferior da escala é ocupado pelos alunos de cursos que se dirigem à formação de professores de ensino fundamental e médio e, no extremo oposto, se destacam aqueles com mercados e prerrogativas profissionais mais garantidas, independentemente da área de conhecimento ou disciplina. Essa forte associação - entre as condições de origem e posição social, a situação no ciclo de vida e os recursos escolares - abrange o conjunto dos indicadores disponíveis, com pequenas variações.

\section{As pretensões quanto ao exercício pro- fissional e o valor do título escolar em di- ferentes mercados}

A ausência de autonomia relativa do espaço escolar se manifesta também no valor atribuído aos destinos profissionais. Como está em pauta um universo composto de alunos e não de profissionais no período pós-universitário, as informações são relativas às pretensões e não ao ingresso e atuação efetiva em algum mercado profissional específico. Assim, evidentemente, as respostas não podem ser tomadas como equivalentes ao futuro profissional, mas como pretensões com alguma probabilidade de realização ou, então, como expectativa, o que não deixa de estar relacionado com as possibilidades reais (BOURDIEU, 1974). Em todo caso, o mais importante a ressaltar é que, além das relações entre as pretensões quanto ao exercício profissional e as condições de origem e o trajeto social e escolar, entram em pauta as avaliações e expectativas frente aos diferentes mercados para os quais o título escolar pode significar um recurso de entrada.

Para o Enade 2005, a questão relativa às pretensões de exercício profissional apresenta as seguintes alternativas de resposta: a) já tem trabalho na área do curso de graduação e pretende continuar nele; b) trabalha em outra área e pretende buscar outra atividade na área do curso de graduação; c) vai se dedicar às atividades acadêmicas e buscar um curso de pós-graduação; d) vai prestar concurso para atividade em empresa pública; e) vai trabalhar em empresa privada; e f) ainda não se decidiu. Nesse último caso a frequência estatística é quase nula. É claro que não se tratam de alternativas de resposta excludentes, mas o fato de serem apresentadas como tais induzem a optar pela considerada mais afim.

Para além de preferências por modalidades alternativas de exercício profissional, estão em pauta relações com mercados específicos, condicionadas, por um lado, por origens e trajetos anteriores e, por outro lado, pela situação no ciclo de vida e pelas condições sociais, familiares, profissionais 
e escolares atuais. A primeira alternativa, dos que já têm trabalho na área do curso de graduação e pretendem continuar nele, além de um estágio mais avançado nos ciclos de vida, familiar e profissional, também supõe um tipo de relação com a escolarização e com o título escolar da perspectiva da inserção prévia num determinado mercado de trabalho.

Aqueles que trabalham em uma área e buscam outra atividade na área do curso de graduação mantêm uma relação com a escolarização e com o título escolar como recurso de reconversão profissional ou ocupacional. Essa reconversão pode implicar numa mudança profunda no estatuto profissional e social ou, então, meramente a passagem de alguma ocupação inicial e transitória para o ingresso no mercado profissional, no qual o título escolar pode significar uma condição decisiva ou complementar. Isso depende do estágio no ciclo de vida e da situação familiar, além dos recursos escolares e sociais em geral.

Os estudantes que pretendem se dedicar às atividades acadêmicas e buscar um curso de pós-graduação, apesar de sua maior dependência do espaço escolar, tomados sem discriminação por curso, não chegam a constituir uma categoria muito densa, visto que as condições envolvidas são muito variadas. Em todo caso, abarca alunos mais jovens, ainda sem ingresso em algum mercado formal de trabalho, frequentemente com maiores investimentos e resultados escolares.

Para os que pretendem prestar concurso para atividade em empresa pública, apesar da falta de informações mais específicas, mantêm relações próprias com as condições de origem e de escolarização e com a titulação escolar, geralmente em condições mais precárias. Mas, deve-se considerar que, mais que atividades profissionais, tudo indica referir-se a um conjunto de mercados específicos, no qual o ingresso através de concurso pode constituir um critério geral.

Algo semelhante ocorre com a alternativa de trabalhar em empresa privada, visto que está em questão um tipo de organização e, o que parece mais importante, com seus próprios recursos e princípios de recrutamento e hierarquização. Apesar da generalidade da categoria, isso fica evidente pelos atributos sociais daqueles que preferem essa alternativa, sistematicamente eles estão posicionados no extremo superior tanto em termos sociais como escolares.

No Enade 2005, os resultados para essa questão configuram uma oposição na qual, no extremo de um dos polos se situam aqueles que já têm trabalho na área do curso de graduação e pretendem continuar nele, seguidos pelos que trabalham em outra área e pretendem buscar uma alternativa na área do curso de graduação. Uma das principais características desse polo é sua associação com aqueles que já estão inseridos num determinado mercado de trabalho específico ou visam ingressar através da titulação no curso de graduação. No extremo oposto se destacam os que aspiram trabalhar em empresa privada e os que visam realizar concurso para ingressar em empresa pública. Numa posição intermediária, mas tendendo para esse segundo polo, se situam aqueles que pretendem se dedicar a atividades acadêmicas e buscar um curso de pós-graduação. Como no Brasil "atividades acadêmicas” têm sentido de "universitárias", tudo indica que tanto para os formuladores da questão como para os respondentes, isso seja equivalente ou próximo da pretensão de se tornar professor de ensino superior. 
A configuração resultante, independentemente da distribuição por cursos e outros condicionantes, tem, numa ponta, a empresa privada como destino profissional associado àqueles com melhores condições sociais e escolares. Ou seja, essa associação forte entre posição social dominante e recursos escolares configura exatamente o polo que representa, nos estudos de Bourdieu $(1984$; 1989), o menor grau de independência do campo escolar. Enquanto no extremo oposto se localizam os que já têm trabalho na área do curso de graduação, por isso a escolarização universitária representa um instrumento de reforço na reconversão profissional e social e, em termos de cursos, sempre os de licenciatura e bacharelado como os mais associados.

Essas oposições contemplam o conjunto das dimensões relativas aos recursos de origem e à situação no ciclo de vida, familiar e profissional na aquisição de capital e titulação escolar, incluindo tanto a escolarização prévia, o curso universitário e as condições de sua utilização, quanto as fontes de seu custeio, as condições de existência e os respectivos mercados específicos, o turno dos estudos, o grau de sucesso ou de fracasso escolar, e assim por diante.

Para uma melhor caracterização, pode-se atentar para a renda mensal da família: os que pretendem trabalhar em empresa privada têm participação maior nas faixas mais altas, particularmente, naquela de trinta salários mínimos ou mais $(6,1 \%)$; em oposição àqueles que trabalham em outra área $\mathrm{e}$ pretendem buscar uma atividade na área do curso de graduação $(1,0 \%)$. No outro extremo, sobressaem os que pretendem se dedicar às atividades acadêmicas (35,8\%). Porém, como a pergunta não especifica, a "renda mensal da família" pode estar referida ao grupo familiar de origem ou por aliança.
Certamente, é por isso que, nesse caso, uma das categorias mais desprovidas de recursos, isto é, aqueles que já têm trabalho na área e pretendem continuar nele, não sejam localizados nas faixas de renda mais baixas, embora também tenham participação abaixo da média nas faixas mais altas. Quanto ao grau de escolarização, praticamente o dobro (33,3\% contra $16,4 \%$ do conjunto do universo) dos que pretendem trabalhar em empresa privada têm pai com curso superior completo. Ao passo que, no extremo oposto se evidenciam, com pouco mais da décima parte $(11,0 \%)$, aqueles que trabalham em outra área e pretendem buscar uma atividade na área da graduação, seguidos pelos que já têm trabalho e pretendem continuar nele $(15,8 \%)$ e os que pretendem se dedicar às atividades acadêmicas e buscar um curso de pós-graduação (16,2\%). 0 inverso ocorre com os graus mais baixos de escolarização do pai, sendo mínima $(2,9 \%)$ a participação daqueles que pretendem trabalhar em empresa privada na faixa dos que o pai não tem qualquer escolarização.

Desse modo, as condições de origens diferenciadas têm efeito muito direto nas relações entre os percursos escolares e profissionais, e na quantidade de tempo e outros recursos investidos na escolarização universitária. Uma das manifestações disso está na intensidade do exercício profissional ou ocupacional durante o curso de graduação. Uma proporção de mais de um terço $(43,5 \%$ contra $17,9 \%$ do conjunto do universo) daqueles que pretendem trabalhar em empresa privada nunca exerceu atividade remunerada. Enquanto no outro extremo, entre os que trabalham 40 horas ou mais, que abrange uma proporção próxima da metade $(44,7 \%)$ do conjunto do universo, encontram-se menos de um terço $(27,2 \%)$ dos que pretendem trabalhar em 
empresa privada e mais da metade daqueles que já tem trabalho na área e pretendem continuar nele (52,3\%). Embora não possa ser exposto em detalhes, isso tem efeitos sobre uma série de outros atributos sóciodemográficos, que representam recursos e que condicionam o acesso e os usos do capital escolar, a começar pela situação no ciclo de vida, que se manifesta nas diferenças de idade, ao estudo civil e à divisão sexual.

Diretamente associado ao trajeto escolar e às condições de acesso ao ensino universitário e sua compatibilização com a carreira profissional, essas condições diferenciadas se manifestam no turno frequentado. Mais de um quinto $(23,6 \%)$ dos que pretendem trabalhar em empresa privada frequentam o turno diurno integral, contra pouco mais da décima parte $(11,5 \%)$ do conjunto do universo e apenas a metade disso (5,3\%) dos que têm trabalho em outra área, mas pretendem trabalhar na área do curso de graduação. Ainda quanto ao trajeto escolar, isso se manifesta no tipo de curso do ensino médio, em que os que pretendem trabalhar em empresa privada se destacam pela maior quantidade dos que concluíram o curso comum de educação geral no ensino regular (73,9\%), em detrimento dos que já têm trabalho na área e pretendem continuar nela (37,8\%). E, com maior proporção dos que concluíram o magistério de $1^{\text {a }}$ a $4^{\text {a }}$ série (36,4\% contra $21,6 \%$ do universo), preponderam aqueles que concluíram o curso profissionalizante técnico no ensino regular. Conjuga-se a isso a concentração dos que pretendem trabalhar em empresa privada entre aqueles que realizaram todo o curso médio em escola privada (44,4\% contra $24,4 \%$ do conjunto do universo), enquanto os que trabalharam em outra área e pretendem buscar uma atividade na área da graduação se concentram entre os que cursaram todo o ensino médio em escola pública.
Tais expectativas de exercício profissional estão associadas com o curso frequentado. Entre os cursos incluídos no Enade 2005, para os que pretendem trabalhar em empresa privada, encontram-se aqueles relacionados às engenharias e arquitetura e urbanismo. Os que já têm trabalho na área e pretendem continuar nele estão mais diretamente associados com cursos como pedagogia, computação, ou seja, cursos de aplicação prática imediata ou de formação de professores de ensino fundamental e médio.

Essa distribuição está aliada à divisão entre licenciaturas e os demais cursos, assim mantêm relações com o exercício do magistério de ensino fundamental e médio. Acima da metade $(51,8 \%)$ do conjunto do universo do Enade 2005 têm experiência no magistério. Porém, essa proporção é de menos da terça parte $(31,8 \%)$ para aqueles que pretendem trabalhar em empresa privada e também para aqueles que atuam em outra área, mas visam buscar uma atividade na área da graduação $(32,1 \%)$, sendo de mais de $4 / 5(81,6 \%)$ para aqueles que já têm trabalho na área e pretendem continuar nele.

0 quadro dessas posições se mantém inclusive no que se refere a alguns indicadores de desempenho escolar. Assim, quanto ao conceito no Enade 2005, os que pretendem trabalhar em empresa privada apresentam uma proporção bem mais alta que o conjunto $(5,8 \%$ contra $3,6 \%$ do conjunto do universo) com o maior conceito. No extremo oposto se destacam aqueles que já têm trabalho na área e almejam continuar nele e os que trabalham em outra área e pretendem buscar uma atividade na área do curso de graduação.

Como já foi dito, os dados relativos ao Provão 2003 têm a vantagem de incluir uma maior quantidade e variedade de cursos. 
A exemplo dos alunos do ENADE 2005, esses do Provão 2003, no que tange às pretensões de exercício profissional, também foram submetidos a um teste de análise de correspondência múltipla, restrito aos que responderam ao questionário socioeconômico, com as seguintes variáveis ativas: a categoria administrativa da instituição, a organização acadêmica da instituição, estado civil, número de irmãos, número de filhos, cor/raça, com quem morou a maior parte do período do curso, renda familiar, número de membros da família que moram junto, grau de escolarização do pai, grau de escolarização da mãe, tipo de escola de ensino médio, curso de ensino médio, idade, conceito no Provão 2003 e nota padronizada da prova geral (média de 500 pontos e desvio padrão de 100). Como variáveis ilustrativas: as pretensões quanto ao exercício profissional e as expectativas quanto à continuidade dos estudos. Nesse teste, o primeiro eixo fatorial alcança 8,35\% (0,2925 de valor próprio), o segundo eixo $3,50 \%$ ( 0,1226 de valor próprio) e o terceiro eixo 3,40\% (0,1190 de valor próprio). As variáveis que mais contribuem para a formação do primeiro eixo são as que seguem: idade $(13,2 \%)$, com quem morou durante a maior parte do período do curso $(11,9 \%)$, estado civil $(11,5 \%)$, número de filhos $(11,3 \%)$, grau de escolarização da mãe $(11,1 \%)$, grau de escolarização do pai $(11,0 \%)$, tipo de ensino médio ( $8,1 \%)$, número de irmãos (7,0\%). Com contribuições menores nesse primeiro eixo: tipo de escola no ensino médio (5,2\%), conceito no Provão 2003 (2,1\%), nota padronizada da prova geral $(1,1 \%)$, cor/raça $(1,2 \%)$, renda familiar $(3,9 \%)$, número de membros da família que moram junto $(0,2 \%)$, organização acadêmica da instituição $(0,5 \%)$ e categoria administrativa da instituição $(0,5 \%)$. Portanto, são apenas algumas variáveis que pesam na formação desse primeiro eixo, em geral, vinculadas às relações com o grupo familiar e às origens sociais. 0 segundo eixo é formado particularmente pela contribuição das seguintes variáveis: categoria administrativa da instituição $(25,8 \%)$, organização acadêmica da instituição (15,1\%), conceito no Provão 2003 (10,8\%), grau de escolarização do pai (7,7\%), grau de escolarização da mãe $(6,9 \%)$, número de membros da família que moram junto $(6,9 \%)$, e com quem morou durante a maior parte do período do curso $(7,8 \%)$. Com contribuição menor: estado civil $(0,3 \%)$, número de irmãos $(2,5 \%)$, número de filhos $(0,7 \%)$, cor/raça $(2,9 \%)$, renda familiar (5,2\%), tipo de escola do ensino médio $(0,7 \%)$, tipo de curso do ensino médio (2,3\%), conceito no Provão 2003 (0,8\%), nota padronizada da prova geral do Provão 2003 (3,8\%) e idade $(0,3 \%)$. Portanto, nesse segundo eixo as principais contribuições são das variáveis relativas à inserção na escolarização universitária e nas relações da família de origem com a escolarização.

Adicionou-se à questão relativa às expectativas profissionais uma vinculada às pretensões de exercício profissional específica para cada curso, e outra condizente com a expectativa de continuidade dos estudos após o curso de graduação. No Provão 2003 as alternativas de resposta à pergunta geral relativa às pretensões de exercício profissional são as que seguem: a) pretende procurar emprego na área do curso de graduação; b) já tem emprego na área e pretende continuar na mesma atividade; c) pretende abrir negócio na área do curso de graduação; d) pretende começar ou continuar trabalhando em outra área; e) não pretende trabalhar.

Apesar das semelhanças com as alternativas de resposta oferecidas no Enade 2005, nesse caso há um grau de especificação me- 
lhor, pelo menos no que tange a alguns aspectos. No entanto, para o Provão 2003, a primeira alternativa dos que pretendem procurar emprego na área do curso de graduação, acaba tendo igualmente um efeito de divisor conforme o estágio no ciclo de vida e a situação familiar, visto que inclui particularmente aqueles com pretensões de ingresso no mercado de trabalho com base no título escolar. A segunda alternativa é equivalente àquela exposta no Enade 2005, mas a terceira (dos que pretendem abrir negócio na área) é muito elucidativa para boa parte dos cursos. Ela pode contribuir para captar um tipo de relação com a escolarização universitária que tem como perspectiva e base social a instrumentalização dessa escolarização, e do respectivo título, tendo em vista os interesses ligados a algum "negócio". Como as informações indicam, isso não se aplica apenas às chamadas "profissões liberais", mas inclui cursos de licenciatura, através da pretensão de abertura de escola própria, com relações muito específicas com os recursos de origem social e trajeto escolar. A quarta alternativa (dos que pretendem começar ou continuar a trabalhar em outra área) também acaba sendo muito elucidativa, visto que apesar de demasiadamente genérica, tem o mérito de indicar um uso social do título escolar mais "externo", sem pretensões de inserção no respectivo mercado de trabalho, mas envolvendo determinados investimentos escolares. Por fim, a quinta alternativa (daqueles que não pretendem trabalhar) tem igualmente muita relevância, visto se tratar de uma relação com o universo e com o título escolar ainda mais "externa” no que concerne ao mercado de trabalho, cuja existência pode decorrer de diferentes razões, tais como o relativo fracasso escolar ou a disponibilidade de recursos sociais que dispensam o ingresso no mercado de trabalho.
No tratamento dos dados, num primeiro eixo de oposição verificam-se no primeiro polo aqueles que já têm emprego na área do curso e pretendem continuar nele, correspondendo às condições sociais e escolares mais precárias, maior número de irmãos, negros ou pardos, os casados ou divorciados/separados, com renda familiar mais baixa, com pai e mãe sem qualquer escolarização ou apenas com o ensino fundamental até a $4^{\text {a }}$ série, com mais filhos, morando com o (a) esposo (a), e com idade mais alta. Em termos escolares, estão mais diretamente associados aos que realizaram todo o ensino médio em escola pública, tendo concluído o curso de magistério de $1^{\text {a }}$ a $4^{\text {a }}$ série no ensino médio ou o supletivo. No Provão 2003 eles estão associados aos conceitos mais baixos. Em termos de expectativas de exercício profissional, esse primeiro polo é correspondente aos que não intencionam fazer qualquer outro curso e aqueles que pretendem fazer algum curso de aperfeiçoamento e/ou especialização.

No polo oposto nesse primeiro eixo, correspondendo aos que pretendem procurar emprego na área do curso de graduação e às melhores condições sociais e escolares, se sobressaem mais intensamente os que possuem renda familiar mais alta, solteiros, com pais com grau de escolarização mais alto e especialmente com curso superior ou médio, sem filhos, mais jovens, morando com amigos ou com os pais e/ou outros parentes, com menos irmãos, e proporcionalmente há mais brancos. Em termos escolares, localizam-se os que cursaram e concluíram o ensino médio regular em escola privada, com maior proporção de matriculados em universidade, em instituição federal. Eles estão mais diretamente associados aos conceitos mais altos (particularmente 5 e 4) e, no que tan- 
ge às pretensões de continuidade de estudos, correspondem mais diretamente aos que visam fazer mestrado e/ou doutorado.

No segundo eixo, um primeiro polo corresponde aos que vislumbram abrir um negócio próprio na área e aos que intentam trabalhar ou continuar trabalhando em outra área que não aquela do curso de graduação. Esse polo é socialmente diferenciado e tem as piores condições quanto ao desempenho escolar, no qual se destacam os que têm renda familiar média ou baixa, com pais com apenas o ensino fundamental, casados, morando com o (a) esposo (a) e/ou filhos (as), ou com os pais e/ ou outros parentes, com maior proporção de brancos, com poucos filhos e irmãos. Mas o que mais caracteriza esse polo são os recursos escolares, em geral mais fracos, com maior proporção dos que no ensino médio concluíram o curso técnico, estudam em faculdades, escolas e institutos superiores ou em faculdades integradas ou centros universitários, matriculados em instituição particular ou municipal, e no Provão 2003 estão mais próximos de conceitos médios ou baixos (3 e 2). Quanto às pretensões de continuidade dos estudos, a esse polo correspondem mais diretamente os que pretendem realizar algum curso de aperfeiçoamento ou de especialização.

No polo contrário nesse segundo eixo, há, do mesmo modo, uma relativa heterogeneidade em termos de origens sociais, mas melhores condições em termos escolares. Neste localizam-se aqueles que têm pais com grau de escolarização muito baixo, embora, numa menor proporção, incluam-se também aqueles com pai e mãe com curso superior, com renda familiar muito baixa, morando com amigos ou sozinhos; outra parte mora com mais que seis membros da família e com vários filhos, com muitos irmãos, sendo a maioria de cor parda. Em termos escolares, eles estão mais associados aos que concluíram o magistério de $1^{\text {a a }} 4^{\mathrm{a}}$ série, matriculados em instituição federal ou estadual, em universidade, tendo realizado todo o ensino médio em escola privada. No Provão 2003, encontram-se entre aqueles com conceitos altos (particularmente 5) e, na nota padronizada da prova geral, estão mais diretamente relacionados às maiores médias. Ou seja, apesar de manifestarem indicadores sociais baixos, há uma inserção escolar relativamente melhor em termos institucionais e em termos de desempenho. Nesse polo (se bem que com fraco grau de associação), situam-se tanto os que pretendem procurar emprego na área do curso de graduação como os que não pretendem trabalhar.

Além da pergunta mais geral relativa às expectativas de exercício profıssional e à continuidade dos estudos, como já mencionado, para os alunos que participaram do Provão 2003 foi apresentada também uma questão específica para cada curso quanto à modalidade particularmente preferida. Mesmo assim, em geral, ocorrem algumas oposições básicas, tais como a atuação em empresa privada ou pública, o exercício no magistério pré-universitário ou no ensino superior ou, ainda, em outras modalidades, a maior adesão às possibilidades de carreira ou o abandono e/ou procura de outra área e atividade, e assim por diante. Todas essas oposições mantêm uma relativa homologia com as origens sociais, com as condições familiares e com o percurso escolar.

Apesar de não ser possível expor em detalhes os resultados, é importante acentuar que a estrutura de oposições resultante é muito semelhante àquela constatada para as pretensões quanto às modalidades de exercício profissional no Enade 2005. Nesse 
caso do Provão 2003, um dos principais polos, condizente com os indicadores sociais e escolares em piores condições, é constituído por aqueles cujo destino ocupacional é o magistério nos níveis de ensino fundamental e médio, ou seja, os cursos de licenciatura e de pedagogia. Mas, mesmo no interior desses cursos ocorre uma hierarquização entre os que pretendem se dedicar ao magistério, nos níveis de ensino fundamental e médio e outras modalidades de exercício profissional. No extremo oposto, também a exemplo do Enade 2005, se situam os cursos e modalidades de exercício profissional dirigidos, em primeiro lugar, a atividades em empresa privada e, em segundo lugar, à empresa pública, ao magistério superior e a outras modalidades, com algumas condições específicas, conforme cada curso, mas sempre de acordo com essas tendências gerais. Portanto, a configuração apresentada com base no conjunto dos alunos, com algumas variações específicas, pode ser constatada em suas tendências principais em cada um dos cursos analisados.

\section{Considerações finais}

0 problema central abordado neste artigo são as condições diferenciadas de ingresso no mercado escolar e as pretensões quanto ao destino ocupacional, tendo como principal fonte os microdados do Provão 2003 e do Enade 2005. Conforme a hipótese geral, nas condições em pauta, a oposição entre as áreas de conhecimento ou disciplinas "básicas" e "aplicadas" torna-se menos importante na estruturação do espaço escolar, frente às condições de ingresso no mercado escolar e de trabalho. A principal razão disso decorre do fato de que a divisão entre as disciplinas "básicas" e "aplicadas" deixa de ter maior peso quando relacionadas aos respectivos mercados profissionais, divididos entre aqueles com maior valor econômico e os dirigidos à formação de professores para o ensino nos níveis pré-universitários, nos quais se concentram as disciplinas "básicas", dentre outras de menor valor econômico e social.

Quer dizer, nas condições em questão, não chega a se configurar alguma dissociação significativa entre as condições e recursos sociais e escolares, que consiste no principal indicador do grau de autonomia escolar, como demonstrado para outras configurações nacionais. Além disso, no caso analisado, no qual o determinante - mais que uma oposição entre disciplinas ou áreas de conhecimento - são as condições de ingresso no mercado escolar e as enormes diferenças entre os distintos mercados profissionais de destino; e afora os indicadores de origem e posição social, passam a ser decisivas outras condições sociodemográficas, vinculadas às relações com o grupo familiar e com o estágio no ciclo de vida e, consequentemente, com a quantidade de tempo disponível para investimentos escolares.

0 principal resultado disso, no que tange ao problema da autonomia do espaço escolar, é que, tomando pelas pretensões quanto às modalidades de exercício profissional, o topo da hierarquia é sistematicamente ocupado por aqueles que pretendem ter como mercado de destino a atuação na "empresa privada”, quer dizer, aquilo que representaria o polo com menor autonomia escolar em outras situações (BOURDIEU, 1984; 1989). No extremo oposto, prepondera o magistério no ensino nos níveis fundamental e médio e, secundariamente, o emprego em empresa pública e as "atividades acadêmicas”, ou seja, como professor de ensino superior, como posições intermediárias, mas pouco definidas, inclusive, pela falta de informações mais específicas. 


\section{Referências}

BOIGEOL, A. e DEZALAY, Y. De l'agent d'affaires au barreau: les conseils juridiques et la construction d'un espace professionel, Genèses, 27, p. 4968, juin.1997.

BOURDIEU, P. Avenir de classe et causalité du probable. Actes de la recherche en sciences sociales, XV, p. 3-42, 1974.

BOURDIEU, P. e CHRISTIN, R. La construction du marché: le champ administratif et la production de la politique du logement. Actes de la recherche en sciences sociales, 81/82, mars, 1990.

BOURDIEU, P. e SAINT MARTIN, M. de. Agrégration et segrégation: le champ des grandes écoles et le champ du pouvoir. Actes de la recherche en sciences sociales, Paris, (69), p. 2-50, 1987.

BOURDIEU, P. Homo Academicus. Paris: Les Éditions de Minuit, 1984.

BOURDIEU, P. La Noblesse d'État. Grandes écoles et esprit de corps. Paris: Les Éditions de Minuit, 1989.

ZELIZER, V. Repenser le marché. La construction du "marché aux bébés" aux Etats-Unis, 18701930. Actes de la recherche en sciences sociales, no 95, sept., p. 3-26, 1992. 
RESUMO

0 objetivo do texto é apresentar a análise das relações entre condições de ingresso no ensino universitário e expectativas de exercício profissional. Com base nos microdados do Enade de 2005 e do Provão de 2003, é apresentada a análise dos indicadores das condições de ingresso e do desempenho nos cursos. A seguir são apresentadas as relações dessas condições com as pretensões de exercício profissional. Conforme a hipótese geral, nas condições estudadas, o capital escolar tem condições muito restritas para apresentar algum grau significativo de autonomia frente a outras espécies de capital. Consequentemente, ao mesmo tempo em que ocorre um forte grau de associação entre os indicadores de origens e de posição social com os recursos escolares, a ocorrência de detenção de capital escolar forte, com relativa independência frente àquelas condições de origem e posição, é muito pouco significativa. Isso se manifesta tanto na divisão entre os cursos como no desempenho escolar e nas preferências por modalidades de exercício profissional.

\section{PALAVRAS-CHAVE}

Espaço escolar. Titulação universitária. Exercício profissional.

\section{ABSTRACT}

The paper presents an analysis of the relationships between conditions of entrance to university and expectations of professional practice, based on the "Provão's" and Enade's microdata in 2005 and 2003. As general hypothesis, in conditions such as those studied, the scholar capital has very strict possibilities to present some significant degree of autonomy compared to others forms of capital. Therefore, while there is a strong degree of association between indicators of origins and school resources, the having of scholar capital is not independent of social origins and conditions. This is observed in the division between the courses, in the academic performances and professional preferences.

\section{KEYWORDS}

University. High education. Professional career. 